\title{
Gender Differences and the Five Facets of Conspiracy Theory
}

\author{
Gary Popoli ${ }^{1} \&$ Angel Longus ${ }^{1}$ \\ ${ }^{1}$ Psychology Department, Stevenson University, United States \\ Correspondence: Gary Popoli, Psychology Department, Stevenson University, United States.
}

Received: July 14, 2021

doi:10.5539/ijps.v13n3p64
Accepted: August 23, 2021

Online Published: August 30, 2021

\begin{abstract}
Although research examining conspiracy theory beliefs has been examined, there is conflicting literature on the relationship between gender and conspiracy thinking. Before this study, little research has been conducted on the differences between males and females in each of the five facets of conspiracy theory. This study was designed to investigate differences in gender as they pertain to government malfeasance (GM), malevolent global conspiracies (MG), extraterrestrial cover-up (ET), personal well-being (PW), and control of information (CI). It was hypothesized that there are statistically significant differences between females and males when it comes to conspiracy theory beliefs for each of the five facets. Archival data from 2016 containing responses to the Generic Conspiracist Beliefs Scale was analyzed. Results supported the main hypothesis of this investigation that significant differences do, in fact, exist between females and males in all five facets of conspiracy theory: government malfeasance, malevolent global conspiracies, extraterrestrial cover-up, personal well-being, and control of information. In addition, this study revealed that females score higher than males in all facets. In general, a computed total conspiracy belief score demonstrated that females $(M=45.10, S D=15.07)$ were significantly higher than males $(M=42.13, S D=15.90)$. Nevertheless, some recent research has reported that women were significantly less likely than men to engage in 'conspiratorial thinking' and endorse a conspiracy about the COVID-19 pandemic of 2020. These findings may be suggesting a change in direction for gender differences and a need for further research.
\end{abstract}

Keywords: conspiracy theory, facets of conspiracy theory, gender, generic conspiracy beliefs scale

\section{Introduction}

Despite the widespread belief of conspiracy theories in popular culture, the psychology behind conspiracy theory beliefs is a topic in which little research has been conducted. According to Zonis and Joseph (1994), "conspiracy theory beliefs can be described as the pattern of explanatory reasoning about events and situations of personal, social, and historical significance in which a 'conspiracy' is the dominant or operative actor (p. 443)." Conspiracies are most prevalent where there is minimal or conflicting information about a topic, or when the public offers incomplete explanations for impactful events (Seide, 2021). When faced with mystery, people create conspiracy theories to make up for the unthinkable such as mythological creatures, extraterrestrial lifeforms, celebrities faking their own deaths, and even the paranormal to feel safer. Conspiracy theories are especially prominent in Western cultures. From the 9/11 terrorist attack on the World Trade Center (Swami et al., 2010), the spread of COVID-19 (Cassese et al., 2020), the faking of the Moon landing, the assassination of John F. Kennedy, and even UFO coverups (Harrison \& Thomas, 2000), people have put their faith in conspiracy theories to explain the unknown.

Conspiracy theory beliefs are divided into five facets: government malfeasance (GM), malevolent global conspiracies (MG), extraterrestrial cover-up (ET), personal well-being (PW), and control of information (CI) (Brotherton et al., 2013). Government malfeasance can be characterized as government misconduct in which the government is responsible for crimes and terrorist attacks against its own citizens. Malevolent global conspiracies are the beliefs that global elites are controlling important events. Extraterrestrial cover-up is the idea that there are extraterrestrial lifeforms that the government is actively trying to hide. Personal well-being is the notion that the government is intentionally spreading diseases or engaging in mind-control. Lastly, control of information is the suspicion that the government is hiding information from the public.

The Generic Conspiracist Beliefs Scale developed by Brotherton et al. (2013) has been widely used to measure conspiracy theory beliefs. The purpose of the Generic Conspiracist Beliefs Scale is to measure individual differences in generic conspiracist ideation. It also measures each of the five facets of conspiracy theories mentioned above. It will be the assessment used in this study. 
Conspiracy theories can reveal much about a person, as conspiracies are the by-product of a person's curiosity. People are drawn to conspiracy theories for a variety of reasons. For instance, Douglas et al. (2017) found that reasons for believing conspiracy theories can be grouped into three psychological motives: (1) epistemic motives, which are the desire for understanding and certainty to validate these theories (2) existential motives, the desire for control and security and (3) social motives, people's desire to feel good about themselves and the groups to which they belong.

There are some consistent findings that exist in the literature. For example, when someone is uneducated on a topic, they tend to gravitate toward information from unreliable sources and often feel powerless. According to Douglas et al. (2017), people who feel powerless are more inclined to believe in conspiracy theories because people do not like to feel helpless. People like to feel good about themselves, and one of the ways they do that is by obtaining information to which others do not have access. Research also supports the view that those with higher education are less likely than those with lower education to believe in conspiracy theories (van Prooijen, 2016). This is consistent with Swami (2014) who found that people high in analytic thinking believe less in conspiracy theories and with Ballova (2018) who found that high rational thinking corresponds with low conspiracy beliefs.

Findings of other predictors of belief in conspiracy theories such as gender, political party, intuitive cognitive style, intentionality bias, anthropomorphism, and schizotypy are not as consistent (Barron et al., 2014; Barron et al., 2018; Brotherton \& French, 2015). In addition to these predictors, there is evidence to support the concept that someone who believes in one conspiracy theory is much more likely to believe in another conspiracy theory (Swami et al., 2010).

One variable receiving considerable attention in the literature when it comes to belief in conspiracy theory is gender, but the findings are not consistent. While Swami (2010) has reported no sex differences in beliefs about extraterrestrial life, other findings are incompatible. For example, Darwin (2011) reported that females are significantly more likely than men to believe in spiritualism, precognition, psi, and the paranormal. Ward (2020) found that women are higher than men when it comes to magical beliefs. Similarly, females are more likely to have paranormal beliefs and beliefs in afterlife (Irwin, 2001; Murphy-Morgan et al., 2019). However, even though women are more likely than men to claim they have experienced a parapsychological event, and more likely than men to believe in astrology, witches, ghosts, ESP, mediums, and the ability to communicate with the dead, men are much more likely to believe in UFOs, extraterrestrials, and extraordinary creatures (Saide, 2013). The pandemic has boosted paranoia and attentiveness in conspiracy theory beliefs, especially in areas with low adherence to mask mandates (Preidt, 2021). Regarding the COVID-19 conspiracy, studies show that gender is a more reliable predictor of COVID-19 conspiracy beliefs than political affiliation (Anderer, 2020). Casses and Farhart (2020) found that women were significantly less likely than men to endorse a conspiracy about the pandemic. This may have to do with the fact that learned helplessness is a key factor in conspiracy theory beliefs, and research has shown that men are more likely to score higher on learned helplessness than women (Gaskell, 2020). In addition, men are more subject to "conspiratorial thinking", which is the tendency to view major events or problems as a part of a larger plot (Anderer, 2020).

\subsection{Purpose of the Present Study}

There are differences in gender reported in the literature when it comes to a specific conspiracy, but little research exists about differences between males and females when it comes to each of the five facets of conspiracy theory as described by Brotherton et al. (2013). This is the purpose of this investigation. Do gender differences exist in each of the five facets of conspiracy belief: government malfeasance, malevolent global conspiracies, extraterrestrial cover-up, personal well-being, and control of information? Based on prior research, it is hypothesized that significant differences between the genders do exist in these five facets of conspiracy theory. However, considering the lack of research surrounding this topic, this study did not hypothesize which gender was more likely to believe in each of the five facets of conspiracy theory. This investigation was focused on whether significant differences between males and females do exist within each facet and, if so, in which of the five facets are differences present.

\section{Method}

\subsection{Participants}

Data for this study were provided by the Open-Source Psychometrics Project (2019). This website contains interactive responses to a multitude of psychological tests and is recommended for research and entertainment purposes only. The data used for this project were subjects' responses to one of the many online personality tests published from 2012 to 2019. The subjects are anonymous and are told beforehand that their answers will be used for research purposes and are asked to provide accurate answers to the questions presented in the tests they elected to take.

Although there were originally 2,495 subjects who responded to the test, 227 of the cases were removed from the analysis. These cases included participants who refused to identify as male or female and any records containing a value other than $1,2,3,4$, or 5 for any of the 15 questions since these are the only acceptable values for those questions. 
The final sample consisted of 2,268 records with 1,183 participants identified as males and 1,085 who identified as females.

\subsection{Measures and Covariates}

The archival data used for this study were last updated in October of 2016 and included the responses of 2,268 subjects who identified as either male or female and recorded a valid score for each question on the Generic Conspiracist Beliefs Scale (GCBS) developed by Brotherton et al. (2013). The GCBS is comprised of 15 questions. For each question, subjects are asked to rate how much they agree with each statement based on a 5-point scale ranging from Disagree (1) to Agree (5). Total scores can range from a low of 15 to a high of 75. Information about the specifics of scoring is not revealed to the participants. Once the test is completed, the scoring process allows the researcher to calculate a total conspiracy belief score for each participant by summing the subjects' scores for all 15 questions on the test. In addition, a total facet score was computed for each of the five facets by summing the three questions that pertained to each of the facets. This provided a mean score for each facet which was used in the analysis.

Although the database contained more than 30 variables for each subject, only the gender of the subject and the subjects' responses to the GCBS were analyzed. It is always a possibility that any of those 30 covariates could act as a confounding variable and influence the outcome of any study, but as an extra precaution, all data that did not meet the specific criteria described above to be considered a valid case were eliminated from the analysis.

\subsection{Research Design}

For this study, the IBM Statistical Package for Social Sciences (SPSS), Version 26 was used for the analysis. An independent samples t-test was performed using gender as the independent variable and total conspiracy belief score as the dependent variable to test for significant differences between males and females with respect to their total conspiracy belief score. To test the main hypothesis of this study that there are significant differences between males and females in each of the five facets of conspiracy theory, a 2 X 5 factorial Analysis of Variance (ANOVA) was performed. Facet and gender were used as the independent or categorical variables while the total facet score for each of the five facets was used as the dependent variable. The five facets were labeled ' 1 ' to ' 5 ' and gender was labeled ' 1 ' for males and ' 2 ' for females. This factorial ANOVA compared the main effects of all five facets of conspiracy theory and gender, in addition to the interaction effects of both on total facet score.

\section{Results}

The final sample for this study consisted of 2,268 individuals. The sample was nearly split in terms of gender with males comprising $52 \%$ of the total and females $48 \%$. A total score on the GCBS was computed for each subject and ranged from a low of 15 to a high of 75 with higher scores representing a greater likelihood to believe in conspiracy theory.

An independent samples $t$-test was conducted to test for significant differences between the two genders based on their total score on the GCBS. Levene's test indicated unequal variances $(F=5.93, p=.015)$ and the degrees of freedom were adjusted from 2266 to 2264 , and the test revealed a statistically significant difference in the total conspiracy belief score for males $(M=42.13, S D=15.90)$ and females $(M=45.10, S D=15.07) ; t(2264)=4.57, \mathrm{p}<.001$. A small effect size was found ( $\mathrm{d}=0.1995 \% \mathrm{CI}[.11-.27])$.

To test for the interaction effects of gender within each of the five facets of conspiracy theory a factorial (ANOVA) was performed using SPSS. Descriptive statistics for the five facets by gender are shown in Table 1. In Table 2, the results of the two-way ANOVA showed a statistically significant interaction between gender within each facet of conspiracy theory based on the belief scores for each gender in each facet, $F(4,11785)=6.159, p<.001$. Main effect analysis demonstrated that females scored higher in conspiracy belief scores than males $(p<.001)$ in all five facets and that the differences were statistically significant. Post hoc comparisons using the Tukey HSD also indicated statistically significant differences between each of the five facets of conspiracy belief theory with the highest mean scores in the Control of Information facet and the lowest in the Extraterrestrial Cover Up facet. 
Table 1. Means and standard deviations for each facet of conspiracy theory by gender within each facet

\begin{tabular}{lllll}
\hline Facet & Gender & $M$ & $S D$ & $\mathrm{~N}$ \\
\hline Malfeasance Government & Males & 9.71 & 3.871 & 1222 \\
& Females & 9.95 & 3.727 & 1137 \\
& Total & 9.82 & 3.804 & 2359 \\
Malevolent Global Conspiracies & Males & 8.14 & 4.260 & 1222 \\
& Females & 8.45 & 3.860 & 1137 \\
& Total & 8.29 & 4.074 & 2359 \\
Extraterrestrial Cover Up & Males & 6.00 & 3.777 & 1222 \\
& Females & 7.15 & 4.053 & 1137 \\
Personal Well Being & Total & 6.55 & 3.954 & 2359 \\
& Males & 7.42 & 3.668 & 1222 \\
Control of Information & Females & 8.23 & 3.699 & 1137 \\
& Total & 7.81 & 3.705 & 2359 \\
& Males & 10.70 & 3.295 & 1222 \\
All Facets & Females & 11.20 & 3.006 & 1137 \\
& Total & 10.94 & 3.168 & 2359 \\
& Males & 8.39 & 4.135 & 6110 \\
& Females & 8.99 & 3.948 & 5685 \\
& Total & 8.68 & 4.057 & 11795
\end{tabular}

Table 2. Tests of between-subjects effects for factorial ANOVA

\begin{tabular}{llllll}
\hline $\begin{array}{l}\text { Dependent Variable: Conspiracy Belief Score } \\
\text { Source }\end{array}$ & Type III Sum of Squares & Df & Mean Square & F & Sig. \\
\hline Corrected Model & $29380.553^{\mathrm{a}}$ & 9 & 3264.506 & 233.526 & .000 \\
Intercept & 890359.615 & 1 & 890359.615 & 63691.762 & .000 \\
Conspiracy Facet & 27771.563 & 4 & 6942.891 & 496.659 & .000 \\
Gender & 1065.823 & 1 & 1065.823 & 76.243 & .000 \\
Conspiracy Facet * Gender & 344.387 & 4 & 86.097 & 6.159 & .000 \\
Error & 164744.823 & 11785 & 13.979 & & \\
Total & 1083421.000 & 11795 & & & \\
Corrected Total & 194125.376 & 11794 & & &
\end{tabular}

a. R Squared $=.151($ Adjusted R Squared $=.151)$

\section{Discussion}

The main purpose of this study was to gain a better understanding of gender differences within each of the five facets of conspiracy theory beliefs and to contribute to the lack of research in this area. Although more research is needed in this area, the present study did support the hypothesis that there are, in fact, significant gender differences within each facet. For our sample, women scored significantly higher than males when it came to government malfeasance, malevolent global conspiracies, extraterrestrial cover-up, personal well-being, and control of information. Whereas past researchers have found inconsistencies in gender for specific conspiracy theories (Barron et al., 2014; Barron et al., 2018; Brotherton \& French, 2015; Swami, 2010), this study was unwavering in its findings that women are more likely than men to believe in each facet of conspiracy theory and to believe in overall conspiracy theory.

Although this study was consistent in its findings, it was not without certain limitations that should be addressed in future research. For example, there were no studies that examined the interaction between gender and facets of conspiracy theory. This made it difficult to predict the direction of the gender differences in each of the five facets. 
Additionally, there is always the caveat that comes with objective tests such as personality inventories in that subjects may not be honest on all questions, thus jeopardizing the reliability of the data and these findings.

Despite these limitations, these results do suggest that, in theory, women are more likely to adapt a conspiracy mindset than men. This predisposition may suggest that not only are women more likely than men to have a generalized attitude toward conspiracy beliefs and the five facets of conspiracy theory, but they may also be more likely to believe in phenomena such as ghosts, spirits, afterlife, and the occult.

However, this pattern may be on the verge of changing. Recent studies have reported that men are more likely than women to engage in 'conspiratorial thinking' and feelings of helplessness, a factor affecting conspiracy beliefs. Most recently, research has reported that men were more likely to accept as true the conspiracy theory surrounding the COVID-19 pandemic than women. Such findings could suggest that, although the differences between genders may well be dependent on the specific conspiracy, recent studies seem to point to the fact that gender differences in conspiracy beliefs may be starting to trend in the opposite direction. Only future research will determine whether males or females are more likely to believe in conspiracies. However, the real question that needs to be answered is, to what degree does the specific facet of conspiracy beliefs predict gender preference?

\section{References}

Anderer, J. (2020, July 28). Perfect storm of uncertainty: Men more likely to believe COVID-19 conspiracy theories. Study Finds.

Retrieved

from https://www.studyfinds.org/men-more-likely-to-believe-coronavirus-conspiracy-theories/

Ballová Mikušková, E. (2018). Conspiracy beliefs of future teachers. Current Psychology, 37(3), 692-701. https://doi.org/10.1007/s12144-017-9561-4

Barron, D., Furnham, A., Weis, L., Morgan, K. D., Towell, T., \& Swami, V. (2018). The relationship between schizotypal facets and conspiracist beliefs via cognitive processes. Psychiatry Research, 259, 15-20. https://doi.org/10.1016/j.psychres.2017.10.001

Barron, D., Morgan, K., Towell, T., Altemeyer, B., \& Swami, V. (2014). Associations between schizotypy and belief in conspiracist ideation. Personality and Individual Differences, 70, 156-159. https://doi.org/10.1016/j.paid.2014.06.040

Brotherton, R., \& French, C. C. (2015). Intention seekers: Conspiracist ideation and biased attributions of intentionality. PLOS ONE, 10(5). https://doi.org/10.1371/journal.pone.0124125

Brotherton, R., French, C. C., \& Pickering, A. D. (2013). Measuring Belief in Conspiracy Theories: The Generic Conspiracist Beliefs Scale. Frontiers in Psychology, 4. https://doi.org/10.3389/fpsyg.2013.00279

Cassese, E. C., Farhart, C. E., \& Miller, J. M. (2020). Gender differences in covid-19 conspiracy theory beliefs. Politics \& Gender, 16(4), 1009-1018. https://doi.org/10.1017/s1743923×20000409

Darwin, H., Neave, N., \& Holmes, J. (2011). Belief in conspiracy theories. The role of paranormal belief, paranoid ideation and schizotypy. Personality and Individual Differences, 50(8), 1289-1293. https://doi.org/10.1016/j.paid.2011.02.027

Douglas, K. M., Sutton, R. M., \& Cichocka, A. (2017). The psychology of conspiracy theories. Current Directions in Psychological Science, 26(6), 538-542. https://doi.org/10.1177/0963721417718261

Gaskell, A. (2020, July 28). Are men more likely than women to fall for conspiracy theories? The Horizons Tracker. Retrieved

from https://adigaskell.org/2020/10/13/are-men-more-likely-than-women-to-fall-for-conspiracy-theories/

Harrison, A. A., \& Thomas, J. M. (1997). The Kennedy assassination, unidentified flying objects, and other conspiracies: psychological and organizational factors in the perception of "cover-up." Systems Research and Behavioral

Science, 14, 113-128. https://doi.org/10.1002/(SICI)1099-1743(199703)14:2<113::AID-SRES154>3.0.CO;2-2

Irwin, H. J. (2001). Age and sex differences in paranormal beliefs after Controlling for Differential Item Functioning. Koestler Chair of Parapsychology. Retrieved from https://hdl.handle.net/1959.11/11357

Murphy-Morgan, C., Neave, N., \& Cooper, C. (2019, April 1). The development and assessment of a new questionnaire to assess beliefs in life after death. Northumbria Research Link. Retrieved from https://nrl.northumbria.ac.uk/37851/

Open-Source Psychometrics Project. (2019 October 15). Retrieved from https://openpsychometrics.org/ 
Preidt, R. (2021, July 29). Pandemic boosted paranoia and conspiracy theories. WebMD. Retrieved from https://www.webmd.com/lung/news/20210729/pandemic-boosted-paranoia-and-conspiracy-theories-study-conf irms

Saide, A. (2013). Gender and the paranormal. Skeptics Society \& Skeptic Magazine, 18(2).

Seide, M. (2021, May 27). Why do we believe in conspiracy theories? Verywell Mind. Retrieved from https://www.verywellmind.com/why-do-we-believe-conspiracy-theories-5181316

Swami, V., Chamorro-Premuzic, T., \& Furnham, A. (2010). Unanswered questions: A preliminary investigation of personality and individual difference predictors of 9/11 conspiracist beliefs. Applied Cognitive Psychology, 24(6), 749-761. https://doi.org/10.1002/acp.1583

Swami, V., Voracek, M., Stieger, S., Tran, U. S., \& Furnham, A. (2014). Analytic thinking reduces belief in conspiracy theories. Cognition, 133(3), 572-585. https://doi.org/10.1016/j.cognition.2014.08.006

van Prooijen, J.-W. (2016). Why education predicts decreased belief in conspiracy theories. Applied Cognitive Psychology, 31(1), 50-58. https://doi.org/10.1002/acp.3301

Ward, S. J., \& King, L. A. (2020). Examining the roles of intuition and gender in magical beliefs. Journal of Research in Personality, 86, 1-13. https://doi.org/10.1016/j.jrp.2020.103956

Zonis, M., \& Joseph, C. M. (1994). Conspiracy thinking in the middle east. Political Psychology, 15(3), 443. https://doi.org/10.2307/3791566

\section{Copyrights}

Copyright for this article is retained by the author(s), with first publication rights granted to the journal.

This is an open-access article distributed under the terms and conditions of the Creative Commons Attribution license (http://creativecommons.org/licenses/by/4.0/). 